\title{
High prevalence of enteroviral genomic sequences in myocardium from cases of endemic cardiomyopathy (Keshan disease) in China
}

\author{
Y Li, T Peng, Y Yang, C Niu, L C Archard, H Zhang
}

\begin{abstract}
Objective-To verify the aetiological involvement of enterovirus and identify the viral genomic sequences in Keshan disease.

Design-Formalin fixed, paraffin embedded myocardial necropsy tissue samples were collected in Keshan disease endemic regions. Fourteen cases with a histologically confirmed diagnosis of subacute or chronic Keshan disease were studied. Control tissue included 10 samples of myocardium from cases of cerebral trauma and one from accidental acid intoxication. One sample from a case of enteroviral myocarditis was used as a positive control. The presence of viral genomic RNA was investigated using an established reverse transcription nested polymerase chain reaction (PCR) coupled with direct nucleotide sequencing. Further investigations of PCR positive samples included in situ antigen detection or hybridisation to confirm positive results.

Results-Nine of 14 myocardial samples from Keshan disease cases and the positive control were positive for the enteroviral RNA. All the controls were negative. Six of the PCR positive samples were investigated further by in situ enteroviral antigen or RNA detection and all were positive. DNA sequencing of six representative PCR products confirmed that they were homologous to the 5' non-translated region of enteroviral genomic RNA. Five had highest homology to coxsackievirus B genotypes and one was identical to poliovirus type 3.

Conclusions-These results support an aetiological role for enteroviral infection in Keshan disease. Nucleotide sequence data suggest that coxsackievirus B or coxsackie B like viruses are often involved in Keshan disease.

(Heart 2000;83:696-701)
\end{abstract}

Keywords: enterovirus; coxsackievirus; cardiomyopathy; Keshan disease

Molecular Pathology Section, Division of Biomedical Sciences, Imperial College of Science, Technology and Medicine, Sir Alexander Fleming Building, London SW7 2AZ, UK

$\mathrm{Y} \mathrm{Li}$

T Peng

L C Archard

H Zhang

Key Laboratory of Viral Heart Diseases of Ministry of Public Health, Shanghai Institute of

Cardiovascular Diseases, Zhongshan Hospital of Shanghai Medical University, Shanghai, People's Republic of China Y Yang

Chuxiong Institute of Keshan Disease, Chuxiong, Yunnan, People's Republic of China

C Niu

Correspondence to: Dr Zhang

h.zhang@ic.ac.uk

Accepted 21 February 2000
Enteroviruses, particularly the group B coxsackieviruses, are the most common agents of viral myocarditis ${ }^{1}$ and are associated with the pathogenesis of dilated cardiomyopathy. ${ }^{2}$ The presence of enteroviral genomic RNA, detected by nucleic acid hybridisation or enzymatic amplification in myocardial samples from different stages of myocarditis and dilated cardiomyopathy, suggests a progression from acute myocarditis to dilated cardiomyopathy. Furthermore, persistence of enteroviral RNA in the heart is an independent predictor of poor prognosis. ${ }^{3}$ Persistence may involve an altered pattern of viral transcription in heart or skeletal muscle. ${ }^{45}$ This has been confirmed in a transgenic mouse model where the production of defective coxsackievirus B3 RNA in the heart leads to the development of a heart muscle disease resembling dilated cardiomyopathy in humans. ${ }^{6}$ Additionally, the enteroviral protease $2 \mathrm{~A}$ cleaves dystrophin in vitro and in coxsackievirus B3 infected mouse heart, and may be a molecular mechanism involved in the pathogenesis of enterovirus associated dilated cardiomyopathy. $^{7}$

Keshan disease was formerly considered to be an endemic cardiomyopathy of unknown aetiology in China. The disease was first observed in Keshan County in northwestern China and occurs exclusively in selenium deficient rural areas occupying a wide zone running from the northeast across the middle of China to the southwest. From 1947 to 1952, a total of 4758 patients in the northeast died of Keshan disease. ${ }^{8}$ There were 2581 cases reported between 1974 and 1983 in the Chuxiong region of Yunan Province in the southwest. The average annual morbidity was $10 / 100000$ population. ${ }^{9}$ During the worst outbreak of Keshan disease in Chuxiong in the 1960s, the morbidity was more than 100/ 100000 population, and mortality reached $98 \% .{ }^{10}$ A national survey conducted between 1990 and 1994 examined a total of 38592 individuals living in Keshan disease endemic regions in 10 provinces. Among these, 1620 were diagnosed as Keshan disease, including 104 new cases, giving an incidence of $0.27 \% .{ }^{11}$ The disease affects predominantly preschool children and women of childbearing age in agricultural families. Clinical features are the acute or chronic episodes of heart disorder characterised by cardiogenic shock, ECG changes (for example, right branch block), and congestive heart failure. Four types of the disease are seen: acute, subacute, chronic, and latent or compensated. The basic pathological change is multifocal myocardial necrosis and fibrous replacement. ${ }^{812}$

In addition to extensive research on the relation between environmental selenium level and Keshan disease, ${ }^{13}$ infectious agents have been implicated. In analogy with viral myocarditis, enterovirus has been isolated from patients with acute or subacute Keshan disease, ${ }^{14}{ }^{15}$ and retrospective serology links enterovirus infec- 
Table 1 Detection of enteroviral RNA in the myocardial tissue from patients with Keshan disease and controls

\begin{tabular}{|c|c|c|c|c|c|}
\hline Patient number & Age (years) & Sex & Diagnosis & $\begin{array}{l}\text { Enteroviral } \\
\text { RT-NPCR }\end{array}$ & $\begin{array}{l}\beta \text { Actin } \\
R T-N P C R\end{array}$ \\
\hline \multicolumn{6}{|l|}{ Keshan disease } \\
\hline 1 & 3 & $\mathrm{~F}$ & SKD & + & + \\
\hline 2 & 3 & M & SKD & + & + \\
\hline 3 & 1 & $M$ & SKD & + & + \\
\hline 4 & 6 & $\mathrm{~F}$ & SKD & + & + \\
\hline 5 & 0.5 & $\mathrm{M}$ & SKD & + & + \\
\hline 6 & 7 & $\mathrm{~F}$ & SKD & + & + \\
\hline 7 & 3 & $\mathrm{~F}$ & SKD & - & + \\
\hline 8 & 21 & M & CKD & + & + \\
\hline 9 & 16 & M & CKD & + & + \\
\hline 10 & 13 & $\mathrm{~F}$ & CKD & + & + \\
\hline 11 & 6 & $\mathrm{~F}$ & CKD & - & + \\
\hline 12 & 25 & $\mathrm{~F}$ & CKD & - & + \\
\hline 13 & 10 & M & CKD & - & + \\
\hline 14 & 22 & M & CKD & - & + \\
\hline \multicolumn{6}{|l|}{ Controls } \\
\hline 1 & 38 & $\mathrm{M}$ & Intoxication & - & + \\
\hline 2 & 26 & $\mathrm{M}$ & $\mathrm{CT}$ & - & + \\
\hline 3 & 23 & $M$ & CT & - & + \\
\hline 4 & 13 & $\mathrm{~F}$ & $\mathrm{CT}$ & - & + \\
\hline 5 & 5 & M & $\mathrm{CT}$ & - & + \\
\hline 6 & 19 & $M$ & $\mathrm{CT}$ & - & + \\
\hline 7 & 31 & $\mathrm{~F}$ & $\mathrm{CT}$ & - & + \\
\hline 8 & 28 & $\mathrm{~F}$ & CT & - & + \\
\hline 9 & 21 & $\mathrm{M}$ & $\mathrm{CT}$ & - & + \\
\hline 10 & 34 & M & CT & - & + \\
\hline 11 & 47 & M & $\mathrm{CT}$ & - & + \\
\hline
\end{tabular}

RT-NPRC, reverse transcription nested polymerase chain reaction; SKD, subacute Keshan disease; CKD, chronic Keshan disease; CT, cerebral trauma.

tion with the disease. ${ }^{16}$ Direct evidence is derived from the use of molecular biological techniques, in that enteroviral genomic RNA was detected in necropsy heart samples from Keshan disease cases by in situ hybridisation ${ }^{17}$ or reverse transcription polymerase chain reaction (RT-PCR). ${ }^{18}$ Nevertheless, interaction between selenium and virus has been observed, in that selenium deficiency increases the cardiovirulence of coxsackievirus B3 by mutations in the viral genome in a mouse model of viral myocarditis. ${ }^{19}$ To establish the aetiological role of enteroviruses in Keshan disease and to characterise the genomic sequence of the viruses involved, we conducted a multicentre study using an established RT-PCR technique coupled with direct nucleotide sequencing. The reliability of these techniques has been evaluated in an experimental model of coxsackievirus B3 myocarditis ${ }^{20}$ and used successfully in our laboratory to identify enterovirus involved in human heart muscle disease. ${ }^{21}$

Table 2 PCR primers used in the study

\begin{tabular}{lll}
\hline Primers & Sequences (5'-3') & Positions \\
\hline Enteroviruses & GGCCCCTGAATGCGGCTAA & \\
F252 & GGGACCTTCCACCACCANCC & $452-470$ \\
R68 & CTACTTTGGTGTCCG & $1177-1196$ \\
F24 & GATAC(T/C)TGAGCNCCCAT & $544-559$ \\
R253 & TTAAAACAGCCTGTGGGTTG & $742-758$ \\
F16 & TCACCGGATGGCCAATCCAA & $1-20$ \\
R5 & CTGGTATCACGGTACCTTTG & $625-644$ \\
F3 & AAACACGGACACCCAAAGTA & $54-73$ \\
R8 & CCCCGGACTGAGTATCAATA & $545-564$ \\
P2 & & $180-199$ \\
Human $\beta$ actin & ATCTGGCACCACACCTTCTACAATGAGCTGCG & \\
HBAF1 & CGTCATACTCCTGCTTGCTGATCCACATCTGC & $263-294$ \\
HBAR1 & TCATCACCATTGGCAATGAG & $750-769$ \\
HBAF2 & CACTGTGTTGGCGTACAGGT & $885-904$ \\
HBAR2 & & \\
\hline
\end{tabular}

^Hybridisation probe

\section{Methods}

PATIENTS AND MYOCARDIAL TISSUE SAMPLES All patients lived in Keshan disease endemic rural areas in the Chuxiong region of Yunnan Province in southwest China. Their hygienic and socioeconomic status was considered low. Fourteen cases of Keshan disease (age range 0.5 to 25 years) occurring between 1983 and 1996 were investigated (table 1). Ventricular tissue was obtained from each patient within 12 hours of death, fixed in $10 \%$ buffered formalin, paraffin embedded, and stored in sealed plastic bags. Histopathological examinations of sections from each sample by Professor $\mathrm{B} \mathrm{Gu}^{8}$ confirmed the clinical diagnosis of subacute Keshan disease in seven cases and chronic Keshan disease in the remainder. All subacute cases died within a week of onset. Control samples were obtained from 11 cases of accidental death occurring between 1985 and 1995, including 10 cases of cerebral trauma and one of acid intoxication (table 1). Among these, eight were from Keshan disease areas and the remaining three were from nonendemic areas. Ventricular tissue was obtained within 12 hours of death. Histologically these hearts were normal. The positive control in this study was explanted myocardium from a patient with chronic myocarditis from a non-endemic area (enteroviral genomic RNA and capsid antigens had been detected in this tissue).

PREPARATION OF TOTAL RNA

Paraffin embedded tissue samples were dewaxed in xylene and washed with ethanol. RNA was recovered by the tri-reagent method according to the supplier's instructions (Sigma, Poole, UK).

REVERSE TRANSCRIPTION AND POLYMERASE CHAIN REACTION

Established reverse transcription nested polymerase chain reaction (RT-NPCR) methods were used to detect enteroviral RNA. ${ }^{2122}$. Details of PCR and second stage nested PCR primers are given in table 2. Primers for enterovirus sequence amplification are targeted to conserved motifs within the 5'NTR or capsid protein coding region of enteroviruses and so they are enterovirus group specific, detecting a broad range of serotypes. For a reverse transcription reaction, total nucleic acid from tissues was used in a volume of $50 \mu \mathrm{l}$, containing $50 \mathrm{mM}$ Tris- $\mathrm{HCl}(\mathrm{pH} 8.3), 70 \mathrm{mM}$ $\mathrm{KCl}, 3 \mathrm{mM} \mathrm{MgCl}, 10 \mathrm{mM}$ dithiothreitol, $0.5 \mathrm{mM}$ dNTPs (Promega), 25 units of RNA inhibitor RNAsin (Promega, Southampton, UK), $0.1 \mathrm{nmol}$ of primer R68, and 200 units of Superscript II RNase $\mathrm{H}$-free reverse transcriptase (Gibco BRL, Paisley, UK). The reaction was carried out at $42^{\circ} \mathrm{C}$ for one hour. PCR was performed on $15 \mu \mathrm{l}$ of the reverse transcription reaction in a total volume of $100 \mu \mathrm{l}$. The following conditions were employed: $10 \mathrm{mM}$ Tris- $\mathrm{HCl}$ (pH 8.3), $50 \mathrm{mM} \mathrm{KCl}$, $1.5 \mathrm{mM} \mathrm{MgCl}_{2}, 0.2 \mathrm{mM}$ dNTPs, primers F252 and R68 or F16 and R5 (0.1 nmol each), and 2.5 units of Taq DNA polymerase (Promega). The cycling reaction involved 
denaturation for one minute at $94^{\circ} \mathrm{C}$, primer annealing for one minute at $55^{\circ} \mathrm{C}$, and template extension for three minutes at $72^{\circ} \mathrm{C}$ for 30 cycles. Second stage nested PCR was performed on $5 \mu$ lof the initial PCR reaction products as described above except for the addition of the nested primers F24 and R253 or F3 and $\mathrm{R} 8$ ( $0.1 \mathrm{nmol}$ each) and reduction of the template extension time to two minutes.

The RT-NPCR for $\beta$ actin was employed to verify the quality of total RNA extracted from tissue samples and was performed similarly, except for the anealing temperature of $65^{\circ} \mathrm{C}$ for first stage PCR and $55^{\circ} \mathrm{C}$ for NPCR.

Precautions taken to avoid false positive results caused by contamination during RTNPCR included the use of filter tips and of separate rooms, containment cabinets, and pipettes for RNA extraction, assembly of reaction mixes, and enzymatic amplification. ${ }^{20}$

PURIFICATION OF NPCR PRODUCTS AND DIRECT SEQUENCING

NPCR products were isolated using a PCR product purification kit (Qiagen, West Sussex, UK). The purified NPCR products were sequenced directly on an automated $\mathrm{ABI}$ model 373A sequencer as described previously. ${ }^{20}$

ANALYSIS OF SEQUENCE DATA

The forward and reverse sequence data from each PCR product were aligned using the SeqEd program (PE-Biosystems, Warrington, UK). The consensus sequence was compared with other amplicons and to the DNA sequence database (GenBank) using the program AssemblyLIGN (Oxford Molecular Group, Oxford, UK) or the GCG group of programs at SERC Seqnet facility, Daresbury, UK.

IN SITU DETECTION OF VIRAL ANTIGENS AND GENOMIC RNA

Paraffin sections were dewaxed and rehydrated by standard histological methods. An enterovirus group specific monoclonal antibody (Mab) 5-D8/1 (DAKO, Cambridge, UK) was used to detect the viral capsid protein VP $1 .{ }^{23}$ Immunostaining was carried out by an indirect immunohistochemistry after heat treatment of sections for antigen retrieval ${ }^{24}$ and the EnVision $^{\mathrm{TM}}$ detection system (Dako, UK) was employed to visualise antibody-antigen complex. For in situ hybridisation, either a mixture of PCR primers (F252, F24, R253, R68, P2; table 2) or a single primer (P2) was labelled with digoxigenin for use as probe. Hybridisation was carried out according to the manufacturer's instructions (Boehringer Mannheim, Bracknell, Berkshire, UK). It was anticipated that multiple primer probes would enhance the hybridisation signal. ${ }^{25}$

\section{Results}

ENTEROVIRAL RNA IN MYOCARDIAL TISSUE FROM KESHAN DISEASE

Total RNA preparations from myocardial tissue samples were amplified by RT-NPCR, initially with primer pairs F252/R68 for the first round PCR and F24/R253 for the nested PCR. Nine of 14 Keshan disease samples and the myocarditis control were positive for enteroviral RNA. As anticipated, the amplified NPCR products were approximately 215 base pairs (bp) long (fig 1A). The reverse transcription products (cDNA) of positive samples were retested with different primer pairs-F16/R5 for the first round and F3/R8 for the nested PCR. The expected 511 bp product was amplified in all samples tested (fig 1A). These results were reproducible in repeated experiments by different workers. In contrast, all 11 normal heart tissue samples were negative. RT-NPCR for the housekeeping gene, $\beta$ actin, was positive in all samples (fig 1B), excluding false negative results. All reagent controls lacking RNA were negative. PCR contamination from the environment was assessed by DNase or RNase (Promega) treatment of the RNA preparations from patients 3, 8, and 9. The PCR positivity was not affected by DNase digestion, but was abolished by RNase treatment. PCR without reverse transcription failed to yield a product (fig 2). These results confirm that the RT-NPCR products seen were not false positives owing to DNA contamination or to cross reactivity with human DNA in the samples.

A

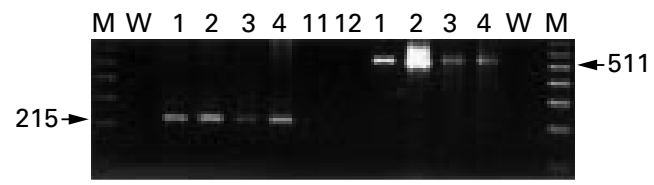

B

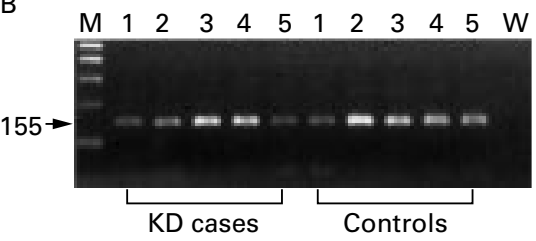

Figure 1 Agarose gel electrophoresis of representative reverse transcription nested polymerase chain reaction (RT-NPCR) products. (A) Enteroviral RT-NPCR products (RT-NPCR) products. (A) Enteroviral RT-NPCR products
amplified with primers F24/R253 (215 bp) or F3/R8 (511 $b p$ ). (B) Representative RT-NPCR products of house keeping gene, $\beta$ actin, from Keshan disease or control heart tissue samples. The first round PCR was with the primer pair HBAF1/R1 and the nested PCR was with the primer pair HBAF2/R2. DNA bands in the $1.5 \%$ agarose gel were stained with ethidium bromide. M, 100 bp markers; $W$, water and reagent control.

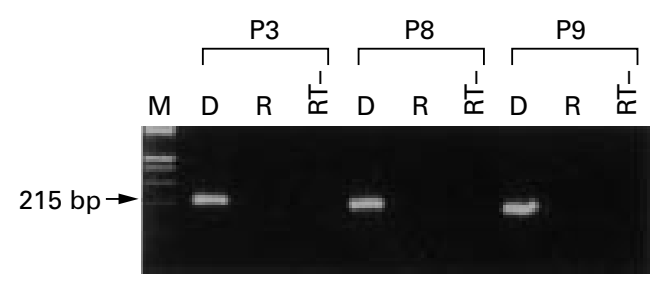

Figure 2 Agarose gel electrophoresis of enterovirus reverse transcription nested polymerase chain reaction (RT-NPCR) products from patients 3,8 , and 9 . The RNA extracts from these three patients were subjected to DNase (D) or RNase (R) treatment before RT-NPCR. PCR was also performed on these samples directly without reverse transcription (RT-). 
Table 3 DNA sequence analysis of nested polymerase chain reaction products

\begin{tabular}{llllll}
\hline $\begin{array}{l}\text { Patient } \\
\text { number }\end{array}$ & $\begin{array}{l}\text { Sequenced } \\
\text { products }\end{array}$ & Sequence identity* & Virus & $\begin{array}{l}\text { Accession } \\
\text { number }\end{array}$ & References \\
\hline 1,2 & F3/R8 & $372 / 420(88.6 \%)$ & CVB3 & M88483 & 29 \\
& F3/R8 & $366 / 420(87.1 \%)$ & Echo 7 & L76401 & 27 \\
& F3/R8 & $365 / 420(86.9 \%)$ & CVB3 & U57056 & 30 \\
$3,8,9$ & F3/R8 & $420 / 420(100 \%)$ & CVB3 & M33854 & 28 \\
& F3/R8 & $417 / 420(99.3 \%)$ & CVB3 & M88483 & 29 \\
& F3/R8 & $405 / 420(96.4 \%)$ & CVB3 & U57056 & 30 \\
4 & & & & & 26 \\
& F3/R8 & $460 / 460(100 \%)$ & Polio 3 & X01076 & 26 \\
& F3/R8 & $459 / 460(99.8 \%)$ & Sabin 3 & X00925 & 31 \\
& F24/R253 & $174 / 175(99.4 \%)$ & CVB3 & M33854 & 28 \\
& F24/R253 & $172 / 175(98.3 \%)$ & CVB3 & M74567 & 32 \\
& F24/R253 & $171 / 175(97.7 \%)$ & CVB3 & M88483 & 29 \\
\hline
\end{tabular}

${ }^{\star}$ Consensus sequence derived from both forward and reverse sequencing of each NPCR product was used for sequence alignment. The first $20-45$ nucleotides in an original sequence data from either direction were not included in consensus sequences because they usually contain ambiguous sequences.

+ positive control.
Bank accession Nos AF198383 and AF198384). ${ }^{27}$ Three cases (3, 8, and 9) were identical to coxsackievirus B3 strain Nancy. ${ }^{28}$ DNA sequences of the NPCR product (primers F24/R253) from the positive myocarditis control showed $97-99 \%$ similarity with coxsackievirus B3. Its GenBank accession No is AF197926 (table 3).

ENTEROVIRAL CAPSID PROTEINS AND GENOMIC

RNA IN SITU IN KESHAN DISEASE HEARTS

Having observed sequences identical to coxsackievirus B3 in samples from three Keshan disease patients, further experiments were performed to exclude the possibility of contamination from environmental or incidental sources by coxsackievirus B3 or its genomic RNA or cDNA, in which case viral antigens or genomic RNA would not be localised in the cytoplasm of myofibres. Tissue sections from patients 3 , $5,6,8,9$, and 10 were examined using in situ antigen detection or in situ hybridisation techniques. Further tissue sections were not available from patients 1,2 , and 4 for in situ detection. Either viral capsid protein VP1 or viral genomic RNA was detected in these six samples by immunohistochemistry using Mab $5-\mathrm{D} 8 / 1$, or by in situ hybridisation using the digoxigenin labelled enterovirus specific probes. Signals were localised in the cytoplasm of affected myofibres (fig 3), confirming the involvement of enterovirus in Keshan disease and the positive results obtained by RT-NPCR. Hybridisation signals were stronger when using multiple oligoprobes than when using a single oligoprobe, as expected. Viral antigen was also detected in sections from the positive control.
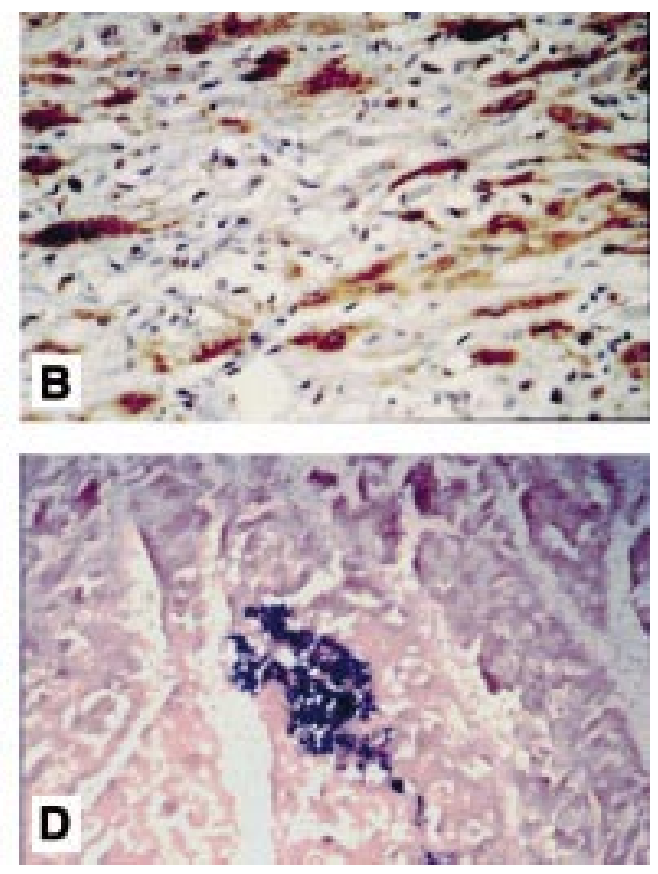

Figure 3 Photomicrographs of heart sections of Keshan disease. (A) Trichrome staining of a section from patient 3 with subacute Keshan disease ( $\times 100$, cytoplasm and muscle fibres stain red, nuclei stain black, and collagen stains blue). (B) Immunohistochemistry staining of a section from the same patient. The brown staining indicates the presence of enteroviral capsid protein VP1 reactive with Mab 5-D8/1 (haematoxylin counterstaining $\times 200$ ). (C) Immunohistochemistry staining of a section from patient 8 with chronic Keshan disease. The brown staining indicates the presence of enteroviral capsid protein VP1 reactive with Mab 5-D8/1 (haematoxylin counterstaining $\times 200$ ). (D) In situ hybridisation on a section from patient 10 with chronic Keshan disease. The dark purple signals indicate the presence of enteroviral genomic RNA probed by the digoxigenin labelled primer mixture (no counterstaining $\times 100)$. 
Enteroviral capsid protein VP1 and genomic RNA were not found in tissue sections of control samples.

\section{Discussion}

Since an outbreak of Keshan disease in 1935, speculation on the aetiology of the disease has been focused on selenium deficiency and virus infection. Selenium is a component of glutathione peroxidase, and deficiency of this antioxidant is linked to cardiovascular diseases, including Keshan disease and cardiomyopathy. ${ }^{33}$ In the present study, exact selenium status of these Keshan disease patients and controls before their death was not known, but Chuxiong Region is noted for selenium deficiency in the environment and in its inhabitants, and is one of the high risk Keshan disease endemic regions. ${ }^{34}$ Selenium supplementation has been instituted in China in Keshan disease endemic areas, but despite restoring the plasma selenium and the decrease in incidence of Keshan disease in last two decades, ${ }^{13}$ the programme has not eliminated Keshan disease. In addition, it is known that Keshan disease has annual and seasonal fluctuation of incidence. ${ }^{8}$ These observations have led to a hypothesis that selenium deficiency (with other nutritional factors, for example vitamin $\mathrm{E}$ ) is an important environmental and nutritional predisposing factor or one of the key interacting factors, but not the only factor in the development of Keshan disease. ${ }^{35}$ One mechanism by which selenium deficiency may act in the pathogenesis of Keshan disease is to increase cardiovirulence of enteroviruses by changes at the viral nucleotide sequence level. ${ }^{19}$ This is supported by a mouse model where the gene for the selenium dependent enzyme glutathione peroxidase 1 (GPX-1) was disrupted (Gpx1-/-). Damage to the heart of $\mathrm{Gpx} 1(-/-)$ mice after infection with an avirulent coxsackievirus was caused by mutations in the viral genome, which generated a cardiovirulent strain. ${ }^{36}$

Enteroviruses were implicated initially in Keshan disease by virus isolation, serology, and recently the detection of enteroviral genomic RNA in the myocardium from patients at different stages of the disease. In one study, 18 of 21 formalin fixed, paraffin embedded necropsy heart tissue samples were positive by RT-NPCR specific for the 5'NTR of enteroviral RNA, but all 10 normal heart tissues were negative. ${ }^{18}$ Some of the same subacute Keshan disease samples had been investigated earlier by an independent laboratory using in situ hybridisation, and 18 of 20 samples were positive for enteroviral RNA. ${ }^{17}$ In this study a cDNA clone of 5 'NTR of coxsackievirus B3 was employed as probe. Similar observations were made in acute or chronic Keshan disease. Naturally, we were concerned about these very high positivity rates, which had not been verified by nucleotide sequencing.

In the present multicentre collaborative study, strict precautions were followed to avoid PCR contamination, and different workers were assigned to repeat the experiments. Enteroviral RNA was detected in nine of 14 patients with Keshan disease (around 65\%), whereas all 11 control samples were negative. The positivity rate was higher in subacute Keshan disease (six of seven cases) than in chronic Keshan disease (three of seven). This prevalence is comparable with previous observations, ${ }^{17}{ }^{18}$ but higher than in other types of heart muscle disease. ${ }^{21}$ This may be accounted for by patient selection, large necropsy tissue samples, and the use of highly sensitive nested PCR techniques. Most of the positive samples were from young patients, who died in the early phase of subacute Keshan disease. Immunohistochemistry results demonstrated extensive viral antigen distribution in these samplesthat is, a large area of myocardium had been infected by enterovirus (fig 3B and our unpublished data).

Sequence analysis of PCR products shows that most enteroviral sequences (five of six) detected in the myocardium from cases of Keshan disease resemble those of coxsackie B-like viruses, in accordance with recent studies on patients with myocarditis and dilated cardiomyopathy. ${ }^{2137}$ However, the 5'NTR sequences of enteroviruses do not necessarily correlate with serotypes, although several phylogenetic clusters could be distinguished on this basis. ${ }^{27}$ Identification of serotype related nucleotide sequences requires analysis of regions coding for viral capsid proteins, for example VP1. ${ }^{38}$

A question that immediately arises is whether the three sequences (in patients 3, 8, and 9) were caused by PCR contamination, and how and when that could occur. Could contamination be excluded? Further experiments suggest that the presence of coxsackievirus B3 sequences identical to the 5 'NTR of the Nancy strain in these samples is unlikely to reflect incidental cDNA or virus contamination because first, the positive RT-NPCR result was not abolished by DNase treatment of the RNA preparation; second, PCR amplification of the RNA extract without reverse transcription failed to yield products; and third, viral capsid protein VP1 and genomic RNA were detected in tissue sections and localised in cytoplasm of myofibres (fig 3).

Enterovirus sequences from one positive sample matched poliovirus type 3 . The significance of this finding is not clear, but myocarditis was observed at necropsy examination in a proportion of patients who died of acute poliomyelitis before the poliovirus immunisation programme. In further studies, poliovirus was isolated from the hearts of three of five persons who died of the disease. These isolates caused not only the characteristic lesions in the anterior horn of monkeys but also myocardial lesions resembling those observed in the human disease. ${ }^{39}$ Another possibility is that the child had a recent dose of live polio vaccine. As no official medical records are available, this speculation cannot be confirmed. However, live polio vaccine boosters had been offered to children within China in the WHO campaign for eradication of poliomyelitis. The enterovirus group specific RT-NPCR would be able to detect poliovirus in blood in heart tissue; as no more tissue from this case is available for in situ 
detection of the viral antigen or RNA, such a possibility cannot be excluded. It is not surprising that the sequence matches wild type poliovirus 3 , as the attenuated strain reversed to neurovirulence within a few days of oral administration of Sabin live vaccine, and the mutants were readily isolated from stool samples. ${ }^{40}$. This is unlikely to be caused by contamination, as wild type poliovirus 3 is not kept in our laboratory.

These data show that enteroviruses are involved in a large proportion of cases of Keshan disease and strengthen the hypothesis that this disorder may be caused by virus infection in an unusual environmental and nutritional setting, where selenium deficiency and other nutrient deficiencies (for example, vitamin E) are predisposing or interacting factors. ${ }^{35}{ }^{41}$ For the first time, nucleotide sequence data show that enteroviruses, mostly in the coxsackievirus B phylogenetic cluster, may be involved as aetiological agents. In addition, our study confirms that archival tissue is suitable for detection of both enteroviral genomic RNA and capsid protein VP1 (with Mab 5-D8/1).

This study was supported by the Ministry of Public Health of China (95-397), the Charing Cross Hospital Trustees Research Committee (97/438), the Wellcome Trust (052954Z97), and partially by the British Heart Foundation. We thank Professo Boqi Gu for his expertise in Keshan disease pathology and Sarah Knowlson for technical assistance.

1 Woodruff JF. Viral myocarditis: a review. Am $\mathcal{f}$ Pathol 1980;101:425-83.

2 Bowles NE, Richardson PJ, Olsen EJ, et al. Detection of Coxsackie B virus specific sequences in myocardial biopsies from cases of myocarditis and dilated cardiomyopathy. Lancet 1986;i:1120-2.

3 Why HJF, Meany BT, Richardson PJ, et al. The clinical and prognostic significance of the detection of enterovirus RNA within the myocardium of patients with myocarditis or dilated cardiomyopathy. Circulation 1994;89:2582-9.

4 Cunningham L, Bowles NE, Lane RJM, et al. Persistence of enteroviral RNA in chronic fatigue syndrome is associated enteroviral RNA in chronic fatigue syndrome is associated
with the abnormal production of equal amounts of positive with the abnormal production of equal amounts of positive and negative

5 Archard LC, Bowles NE, Cunningham L, et al. Molecular probes for detection of persisting enterovirus infection of human heart and their prognostic value. Eur Heart f 1991; 12(suppl D):56-9.

6 Wessely R, Klingel K, Santana LF, et al. Transgenic expression of replication-restricted enteroviral genomes in hear muscle induces defective excitation-contraction coupling and dilated cardiomyopathy. $\mathcal{F}$ Clin Invest 1998;102:144453.

7 Badorff C, Lee GH, Lamphear BJ, et al. Enteroviral protease 2A cleaves dystrophin: evidence of cytoskeletal disruption in an acquired cardiomyopathy. Nat Med 1999;5:320-6.

$8 \mathrm{Gu} \mathrm{BQ}$, Cheng TO. Keshan disease. In: Cheng TO, ed. The international textbook of cardiology. New York: Pergamon Press, 1986:752-65.

9 Chuxiong Keshan Disease Scientific Investigation Team. Summary of a comprehensive scientific investigation on KD in Chuxiong region. In: Yu WH, Wang F, ed. Proceed$\mathrm{KD}$ in Chuxiong region. In: Yu WH, Wang $\mathrm{F}$, ed. Proceed-
ings of comprehensive scientific investigation on KD in ings of comprehensive scientific investigation on KD in
Chuxiong region. Beijing: Peoples Health Press, 1988:1-8.

Chuxiong region. Beijing: Peoples Health Press, 1988:1-8.
Niu CL. Outbreak of KD in Chuxiong region. Chin $\mathcal{F}$ EndeNiu CL. Outbreak
miol 1983;2:85-9.

11 Zhu YX, Wang ZB, Xiang YZ. Five year surveillance of Keshan Disease (1990-1994). Chin F Prev Endemiol 1996; 11:53-6.

12 Li GS, Wang F, Kang DR, et al. Keshan disease: an endemic cardiomyopathy in China. Hum Pathol 1985;16:602-9.

13 Ge KY, Yang G. The epidemiology of selenium deficiency in the etiological study of endemic diseases in China. Am $\mathcal{F}$ Clin Nutr 1993;57(suppl 2):259-63S.

14 Department of Microbiology. Investigation of biological aetiology of Keshan disease. F Chongqing Med Coll 1978;2: $1-5$.

15 Su CQ, Gong QM, Li Q, et al. Preliminary summary of vira etiology of Keshan disease. Chin Med f 1979;59:466-70.
16 Zhong XK, Zhou YC, Yu WH. Detection of Coxsackievirus B neutralisation antibodies in sera from children with KesB neutralisation antibodies in sera from child

17 Zhong XK, Zhang FM, Jiang ZR, et al. Relationship on Coxsackie B viruses and subacute Keshan disease in Yunnan Province using in situ hybridization. Chin $\mathcal{F}$ Endemiol 1993;12:193-5.

18 Li YW, Yang YZ, Chen HZ. Detection of enteroviral RNA in paraffin-embedded myocardial tissue from patients with Keshan disease by nested PCR. Natl Med f China 1995:75. 344-5.

19 Beck MA, Shi Q, Morris VC, et al. Rapid genomic evolution of a non-virulent coxsackievirus B3 in selenium-deficient mice results in selection of identical virulent isolates. Nat Med 1995;1:433-6.

20 Zhang HY, Soteriou B, Knowlson S, et al. Characterization of genomic RNA of coxsackievirus B3 in murine myocarditis: reliability of direct sequencing of reverse transcription-nested polymerase chain reaction products. $\mathcal{F}$ Virol Methods 1997;69:7-17.

21 Archard LC, Khan MA, Soteriou DA, et al. Characterization of Coxsackie B virus RNA in myocardium from patients with dilated cardiomyopathy by nucleotide sequencing of with dilated cardiomyopathy by nucleotide sequencing of products. Hum Pathol 1998;29: 578-84.

22 Ouyang X, Zhang H, Trevor AB, et al. Detection of Coxsackievirus B3 RNA in mouse myocarditis by nested polymerase chain reaction. Clin Diagn Virol 1995;3:23345.

23 Yousef GE, Brown IN, Mowbray JF. Derivation and biochemical characterization of an enterovirus groupspecific monoclonal antibody. Intervirology 1987;28:16370 .

24 Leong ASY, Milios J, Leong FJ. Epitope retrieval with microwaves. Appl Immunohistochem 1996;4:201-7.

25 Trembleau A, Bloom FE. Enhanced sensitivity for light and electron microscopic in situ hybridisation with multiple simultaneous non-radioactive oligodeoxynucleotide probes. F Histochem Cytochem 1995;43:829-41.

26 Cann AJ, Stanway G, Hughes PJ, et al. Reversion to neurovirulence of the live-attenuated Sabin type 3 oral poliovirus vaccine. Nucleic Acids Res 1984;12:7787-92.

27 Pöyry T, Kinnunen T, Hyypiä T, et al. Genetic and phylogenetic clustering of enteroviruses. F Gen Virol 1996;77: 1699-717.

28 Klump WM, Bergmann I, Muller BC, et al. Complete nucleotide sequence of infectious coxsackievirus B3 cDNA: two initial 5' uridine residues are regained during plus-strand RNA synthesis. F Virol 1990;64:1573-83.

29 Lindberg AM, Stalhandske PO, Pettersson U. Genome of coxsackievirus B3. Virology 1987;156:50-63.

30 Knowlton KU, Jeon ES, Berkley N, et al. A mutation in the puff region of VP2 attenuates the myocarditic phenotype of an infectious cDNA of the Woodruff variant of coxsackievirus B3. F Virol 1996;70:7811-18.

31 Stanway G, Cann AJ, Hauptmann R, et al. The nucleotide sequence of poliovirus type 3 leon $12 \mathrm{alb}$ : comparison with sequence of poliovirus type 3 leon 12 alb: comparison
poliovirus type 1. Nucleic Acids Res 1983;11:5629-43.

32 Zhang HY, Yousef GE, Cunningham L, et al. Attenuation of a reactivated myocarditic coxsackievirus B3, 5'nontranslated region does not contain major attenuation determinants. F Med Virol 1993;41:129-37.

33 Huttunen JK. Selenium and cardiovascular diseases-an update. Biomed Environ Sci 1997;10:220-6.

34 Ecology Study Group. Ecological environment of Keshan disease in Chuxiong region. In: Yu WH, Wang F, ed. Proceedings of comprehensive scientific investigation on KD in Chuxiong region. Beijing: Peoples Health Press, 1988:4883.

$35 \mathrm{Xu}$ GL, Wang SC, Gu BQ, et al. Further Investigation on the role of selenium deficiency in the aetiology and pathogenesis of Keshan disease. Biomed Environ Sci 1997;10: 316-26.

36 Beck MA, Esworthy RS, Ho YS, et al. Glutathione peroxidase protects mice from viral-induced myocarditis. FASEB F 1998;12:1143-9.

37 Nicholson F, Ajetunmobi JF, Li M, et al. Molecular detection and serotypic analysis of enterovirus RNA in archival specimens from patients with acute myocarditis. $\mathrm{Br}$ Heart $\mathcal{F} 1995 ; 74: 522-7$.

38 Oberste MS, Maher K, Kilpatrick DR, et al. Molecular evolution of the human enteroviruses: correlation of serotype with VP1 sequence and application to picornavirus classification. F Virol 1999;73:1941-8.

39 Jungeblut CW, Edwards JE. Isolation of poliomyelitis virus from the heart in fatal cases. Am F Clin Pathol 1951;21:60123

40 Minor PD, John A, Ferguson M, et al. Antigenic and molecular evolution of the vaccine strain of type 3 poliovirus during the period of excretion by a primary vaccinee. $\mathcal{f}$ Gen Virol 1986;67:693-706.

41 Levander OA, Beck MA. Interacting nutritional and infectious etiologies of Keshan disease. Biol Trace Elem Res 1997;56:5-21. 